\title{
O LUGAR DAS UTOPIAS NO PENSAMENTO DE RALF DAHRENDORF: CRÍTICA A TALCOTT PARSONS E KARL MARX
}

\section{Antônio Carlos Dias Jr ${ }^{1}$}

\section{INTRODUÇÃO}
“[...] a utopia é sempre liberal, porque não deixa espaço para o erro e sua correção".

(DAHRENDORF,1979)

Ralf Dahrendorf, sociólogo e filósofo inglês de origem germânica, sentia-se pouco confortável sempre que alguém se colocava a rotular seu pensamento. Embora aceitasse e endossasse sua filiação à tradição liberal social, ficava pouco a vontade quando dele se exigia um posicionamento categórico. Não obstante, tendo em vista o conjunto, há opções filosóficas e epistemológicas que caracterizam sua produção intelectual.

A sua aversão aos modelos que considerava totalizantes e utópicos é um desses traços característicos. Talcott Parsons, e sua proposta sistêmico-utópica, e Karl Marx, com sua filosofia da história, os alvos diletos. Dahrendorf, cujo principal pilar teórico é o reformismo liberal, traço característico da geração de intelectuais europeus do pós-guerra que formulou crítica sistemática ao marxismo e ao regime soviético, buscou dirigir sua análise sociológica tendo em vista a realidade concreta das sociedades de seu tempo.

A breve análise empreendida neste artigo diz respeito à produção de juventude de Dahrendorf, vale dizer, ao momento em que o autor consolidava sua trajetória intelectual por meio da crítica teórica aos autores que dominavam o cenário intelectual, no âmbito das ciências sociais, de sua época: Parsons e sua teoria funcionalista do consenso social - que

\footnotetext{
${ }^{1}$ Doutorando em Sociologia pela Universidade Estadual de Campinas - UNICAMP - Bolsista Fapesp (2008). É Mestre em Sociologia (2007) e Bacharel/Licenciado em Ciências Sociais - Habilitação em Sociologia (2004) - pela mesma Universidade. Atualmente desenvolve estágio de doutoramento na École de Hautes Études em Sciences Sociales -EHESS/Paris, e é professor das Faculdades Network e na Faculdade Santa Lúcia.
} 
ventilava ares totalizantes no campo teórico, mas mostrava-se pouco aplicável à realidade, e Marx, que inspirava a partir de seu pensamento a consecução real de um modelo de sociedade alternativo ao capitalismo.

\section{PARSONS E A UTOPIA DA SOCIEDADE SEM CONFLITOS}

Nas obras de Dahrendorf, pode-se perceber claramente a profunda influência do pensamento de Karl Popper, sobretudo sua adesão crítica ao historicismo. ${ }^{2} \mathrm{O}$ caráter intrinsecamente caótico e incerto da realidade social, bem como das respostas que se thes apresentam, constitui o legado maior de Popper ao liberalismo de Dahrendorf. Mais que isso, ao que tudo indica, é o norte de sua visão reformista de sociedade.

A sociedade aberta e seus inimigos, de Karl Popper, [...] é, sem dúvida, uma das publicações mais importantes não apenas da história do liberalismo, mas da história do pensamento político em geral. Popper descreve detalhadamente esta filosofia política da incerteza e da dúvida e, na minha opinião, não restou nada a acrescentar. (DAHRENDORF, 1981a, p. 14) ${ }^{3}$

Dahrendorf, a partir dos preceitos filosóficos popperianos da incerteza e da dúvida, crê que os utopistas possuem em suas obras um traço comum: de Platão, passando por Morus, Hegel e Rousseau, até Orwell, todas as sociedades são concebidas no plano ideal, em que a mudança está ausente bem como os conflitos estruturais. A história (com " $h$ ") seria um rio caudaloso em constante movimento, ao passo que a utopia nada mais seria que uma calma

\footnotetext{
${ }^{2}$ Entenda-se aqui o historicismo como a teoria da lógica, ou significado global, da história. Segundo o entendimento de Popper em The poverty of historicism (1957), a filosofia política do historicismo é concebida como uma abordagem da ciência social com a finalidade de predição; uma aproximação (sobretudo o marxismo) entre a teleologia da história e o totalitarismo; uma cosmovisão, por assim dizer - de cunho economicista nesse caso - que encerraria uma utopia totalitária.

${ }^{3}$ E ainda: "Na verdade sou kantiano, ou, se preferir, popperiano, o que equivale dizer que, para mim, um dos aspectos fundamentais da vida é que o homem não pode responder a todas as questões. [...] Creio haver explicado em Out of utopia que o modelo estrutural-funcionalista de sociedade não admite qualquer tipo de mudança, porque se baseia na ideia de que cada qual desempenhe um papel definido e funcional ao equilíbrio atual da sociedade. [...] $\mathrm{Na}$ realidade a crítica que faço ao estruturalfuncionalismo se resume numa crítica ao hegelianismo [e a Marx]. É uma crítica voltada contra a maneira utópica de encarar a sociedade [...] (DAHRENDORF , 1981a, p. 23).
} 
laguna. Numa palavra, trata-se, segundo o autor, de sociedades sem história (DAHRENDORF, 1974).

A expressão sociológica contemporânea dessa utopia tornou-se o alvo inicial de Dahrendorf: o funcionalismo de Parsons. O eminente intelectual era figura de destaque na sociologia mundial do pós-guerra, influenciando diversas correntes de pensamento, por vezes além do âmbito das ciências sociais.

Segundo Parsons (1984), a teoria sociológica tem que ser sistemática, baseando-se em marcos de referência que transcendam categorias meramente dedutíveis de observações empíricas obtidas apenas dos materiais da própria sociologia, o que equivale a dizer que deve orientar-se segundo quantas categorias oriundas de outras disciplinas (mecânica clássica, biologia etc.) forem necessárias, isto é, deve transcender aos seus próprios limites, criando um sistema fundamental mais amplo.

Desse marco inicial e sempre tendo como base a ação social ${ }^{4}$ empreendida pelo ator, Parsons aponta que a situação da ação compreende objetos sociais e não sociais que se encontram diante do ator da ação como pressupostos incontroláveis ou como instrumentos controláveis. Pode se tratar de um significado difuso ou específico, de objetos ou pessoas, como condições ou meio de ação, mas, de qualquer modo, trata-se de objetos extrínsecos ao ator da ação.

Já os pressupostos intrínsecos à ação - e suas respectivas implicações - estão circunscritos sob o ponto de vista da orientação do ator referente à situação, compreendendo duas espécies distintas de orientação analítica: a orientação motivacional e a de valor. Toda ação pode ser analisada de acordo com suas motivações e é sempre oriunda da vontade do ator e direcionada a um fim, por outro lado toda ação também pode ser analisada sob o

\footnotetext{
${ }^{4}$ Para Parsons, a ação social é qualquer forma de conduta humana que se possa descrever e analisar mediante determinadas categorias, que são produtos - pois que são implicações lógicas - e, ao mesmo tempo, ponto de partida da teoria da ação. A tipologia que estabelece bem como seus desdobramentos são reflexos diretos da influência que recebeu de Max Weber, autor que estudou em seu doutoramento (O conceito de capitalismo nas teorias de Max Weber e Werner Sombart) e de quem foi pioneiro tradutor para o inglês. Autores como Durkheim e Pareto também foram decisivos em sua formação, constituindo influências marcantes. Ver, em português, o estudo elucidativo de José Maurício Domingues, A sociologia de Talcott Parsons (2001).
} 
aspecto da orientação de valor, o que significa dizer que se submete a critérios e normas seletivas, introduzidas pelo ator. ${ }^{5}$

O próximo passo da teoria da ação se concentra em analisar as maneiras em que se podem considerar como integradas dentro de um sistema as ações ou unidades de ação, que não se encontram isoladas no plano empírico, mas em constelações, as quais Parsons denomina sistemas. O teórico distingue então três sistemas básicos: o sistema social, o sistema da personalidade e o sistema cultural.

A análise formal desses três sistemas de ação conduz às teorias propriamente sociológica, psicológica e antropológica, respectivamente. Para Parsons, contudo, esse esquema teórico elementar não consegue englobar a complexidade dos problemas da teoria sociológica. Disso resulta sua teoria estrutural-funcional bem como os conceitos correlatos de estrutura e função. ${ }^{6}$

As categorias estruturais implicam a construção de uma estrutura analítica estável de sistemas não representáveis de modo empírico, ${ }^{7}$ reconhecendo-se, desta maneira, que semelhantes estruturas estáveis não podem jamais se apresentar empiricamente. Dito diferentemente, a construção de uma estrutura, tida como estável, de sistemas sociais representa, logicamente, uma operação na qual se fixam como constantes determinadas características que são, na realidade, variáveis. ${ }^{8}$

Para os processos dinâmicos no interior dos sistemas, Parsons utilizou-se da categoria de função social, introduzida de maneira a proporcionar a conexão entre as categorias sociais estáticas e os elementos variáveis dentro do sistema. A função social, assim, tem o atributo de "aferir a importância dos fatores dinâmicos e dos processos dentro do sistema"

\footnotetext{
${ }^{5}$ As categorias propostas por Parsons para a descrição da orientação dos atores em situações concretas são: 1) de modos passíveis de orientação motivadora; 2 ) de modos passíveis de orientação de valor e; 3 ) de possíveis alternativas na interpretação da situação de ação, enquanto contribuam para a orientação referente a situações (DAHRENDORF, 1981b, p. 43).

${ }^{6}$ Para Dahrendorf, tais conceitos são introduzidos por Parsons “[...] no plano abstrato do sistema teórico com a intenção de racionalizar, descrever e fixar pontos esclarecedores, construídos anteriormente, não explicáveis num sistema simplificado" (DAHRENDORF, 1981b, p. 43).

${ }^{7}$ Nota-se aqui a influência recebida por Parsons de Weber, agora no que se refere à construção típicoideal.

${ }^{8}$ Dahrendorf observa nesse sentido que a categoria estrutura implica, pois, uma perda de plenitude empírica, constituindo assim uma simplificação. Tirada de um contexto processual, as estruturas sociais são, necessariamente, estáticas.
} 
(DAHRENDORF, 1981b, p. 46). Com efeito, um determinado processo social é funcional ou disfuncional ao equilíbrio do sistema social. ${ }^{9}$

As disfunções do sistema, entretanto, são marginais (estados patológicos) e não chegam a ameaçar a estabilidade dos sistemas sociais, vale dizer, não são fortes o suficiente para colocar em risco o sistema de expectativas normativas que define a conduta adequada dos indivíduos que desempenham determinados papéis funcionais num sistema supraindividual e institucionalizado.

Parsons observou, sobretudo em relação às críticas ao seu sistema interpretativo, que a mudança dos sistemas sociais representa, na realidade, o ponto culminante de sua teoria, ${ }^{10}$ mas que a teoria da mudança não seria possível (eximindo-o, pois, da culpa que lhe é imputada) por dois motivos: porque exigiria, primeiramente, um conhecimento tal do conjunto do sistema teórico estático que ainda não estaria disponível no estágio atual (mas que isso seria possível posteriormente); e, depois, por ser refém das "limitações imanentes a uma teoria estrutural-funcional que nasceu do dilema da ausência de conhecimento das 'leis' que determinam os processos dentro do sistema" (PARSONS, 1984, p. 483).

No final das contas, ao que tudo indica, ele pensava mesmo a análise da estática social como a de verdadeira importância, marginalizando, com isso, os aspectos de mudança estrutural. ${ }^{11}$

Dahrendorf, primeiro como crítico a distância e depois quando esteve, em finais da década de 1950, em Palo Alto, nos EUA, não se furtou a dirigir seu arsenal à teoria

\footnotetext{
${ }^{9}$ Os pares análogos aos conceitos de estrutura e função são, respectivamente, status e papel. Por status, Parsons entende a posição ou o local onde o ator está localizado dentro do sistema social e em relação aos outros atores. Por papel, entende o que cada ator realiza em relação aos outros atores.

${ }^{10}$ De fato, o último capítulo de El sistema social (Os processos de mudança dos sistemas sociais) é dedicado, ainda que incipientemente, à mudança estrutural.

${ }^{11}$ A passagem final de Parsons (1984, p. 529) no derradeiro capítulo, que trata da mudança social, é elucidativa nesse sentido: "Talvez se me permita uma palavra final. Tem-se afirmado constantemente que o enfoque 'estrutural-funcional' para as questões teóricas, no campo sociológico, sofre de um prejuízo 'estático'. Afirma-se que os problemas de mudança estão fora de seu alcance - e que evidentemente, ao passo que são estes os problemas verdadeiramente importantes, semelhante teoria só conduziria a libertar-se de uma relevância autenticamente empírica. Talvez os exemplos anteriormente citados contribuam para convencer devidamente o leitor que o autor é ciente de que vivemos, como se diz, em uma sociedade 'dinâmica'. Tampouco seja demasiado esperar que este capítulo o convencerá de que, no embate entre aspectos estáticos e dinâmicos, exista certa falsidade. Se se trata de uma boa teoria, seja quais forem os problemas que a ela se apresentam, não há razão verdadeira para crer não se possa aplicar igualmente tais preceitos aos problemas de mudança de maneira que são aplicados aos processos de sistemas estabilizados".
} 
funcionalista do sociólogo americano. Sua primeira intervenção pode ser encontrada em um texto de 1954, denominado Estrutura e função: Talcott Parsons e o desenvolvimento da teoria sociológica (In DAHRENDORF, 1981b).

Dahrendorf observa que a teoria estrutural-funcionalista parsoniana é irmã da utopia, pois lida com sistemas em equilíbrio, nos quais a mudança histórica inexiste.

\begin{abstract}
A teoria estrutural-funcionalista não introduz pressupostos irrealísticos com o propósito de explicar problemas reais; ela introduz muitas espécies de pressupostos, de conceitos e de modelos com o único propósito de descrever um sistema que nunca existiu e não é provável que venha a existir jamais. (DAHRENDORF, 1974, p. 139)
\end{abstract}

Na visão de Dahrendorf, pois, a teoria parsoniana tratou dos processos descritivos e motivacionais dos atores sem mostrar como estes podem intervir para transformar a si e a realidade social que os cerca.

\begin{abstract}
A teoria sociológica sistemática propõe-se a deter o curso da história, a elevar a um conjunto estruturado seus materiais por meio do espírito cognoscente, ordenador e racionalizador da ciência, e libertar deste modo o homem da sua passiva imersão na história. A dificuldade desta teoria consiste em como voltar a introduzir o elemento do conflito e da mudança no plano da abstração analítica, nos seus modelos e premissas [...] Este problema mostra o ponto em que a teoria estrutural-funcional fracassa na sua forma presente e no que deve fracassar, devido à disposição de suas categorias. (DAHRENDORF, 1981b, p. 52).
\end{abstract}

\title{
3 MARX E A UTOPIA DA SOCIEDADE SEM CLASSES
}

\author{
“É, com efeito, na teoria de classes de Marx que se revelam \\ plenamente a grandeza e a fatalidade de seu trabalho."
}

(DAHRENDORF,1982)

No livro As classes e seus conflitos na sociedade industrial (1982) escrito entre os anos de 1952 e 1954, Dahrendorf assevera que Marx, ao teorizar sobre as classes sociais, confundiu a análise de cunho propriamente sociológico com a especulação filosófica, e isso acabaria por tornar suas análises, do ponto de vista heurístico e empírico, pouco sustentáveis e, por consequência, para o azar de sua sociologia, vagamente válidas. Desta feita, avalia (e este teria 
sido a gênese do equívoco de Marx): confunde-se filosofia da história com análise da dinâmica da sociedade capitalista.

Nesse texto, o autor argumenta com propriedade que, na teoria de classes em Marx, estão imbricadas as raízes do pensamento deste, isto é, pode-se encontrar a aplicação concreta do substantivo classes, utilizado originalmente pelos primeiros economistas políticos britânicos, aplicado às categorias de capitalistas e proletários pelos socialistas utópicos franceses e empregado, consequentemente, na noção de luta de classes, uso este creditado à dialética hegeliana. Com efeito, sua teoria de classes sociais encerra, ao mesmo tempo, um componente sociológico (análise da dinâmica da sociedade capitalista) e ideológico/utópico (filosofia da história).

Disso derivaria que a própria definição do conceito classes sociais em Marx seria fruto da preocupação em formular certas leis do desenvolvimento social e das forças envolvidas nesse processo, e não propriamente em descrever um estado real de sociedade. Trata-se, com efeito, da descrição do conceito pensando-o em termos dinâmicos, e não estáticos; antes analíticos que descritivos.

[...] para Marx, a teoria de classes não tinha por objeto uma seção transversal da sociedade parada no tempo; mais especificamente, não era uma teoria de estratificação social, mas sim um instrumento para explicar as mudanças nas sociedades globais. Ao elaborar e aplicar sua teoria de classes, Marx não se orientava pela pergunta "qual o aspecto real de uma sociedade em um determinado ponto no tempo?", mas sim pela pergunta "como a estrutura de uma sociedade se modifica?". (DAHRENDORF, 1982, p. 29).

Assim o teria feito Marx com o conceito de classes ao colocar antagonicamente duas numerosas classes, burgueses e proletários, sem descrever-lhes as minúcias compositivas, agrupando-as em categorias gerais cuja "legitimidade parece muito mais que duvidosa" (DAHRENDORF, 1982, p. 30), de modo que toda sorte de conflitos existentes na sociedade bem como a direção do desenvolvimento histórico (portanto todo conflito capaz de gerar mudanças estruturais) são de caráter classista (baseado na tese-antítese entre possuidores e não possuidores dos meios de produção), e tais conflitos são sempre os dominantes nas sociedades. Marx teria enveredado por generalizações cuja insustentabilidade empírica seria flagrante. 


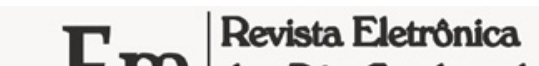

Assim, para Dahrendorf, proposições como "conflito de classes gera mudança histórica" são verdadeiras e de primeiro tipo, ao passo que outras como "a sociedade capitalista é a última sociedade de classes da história" são passíveis de refutação quando confrontadas a fatos empíricos (GIDDENS, 1975).

Marx, em seu esquema analítico das classes sociais, como é consabido, tratou de categorizar os indivíduos que possuem propriedade efetiva dos meios de produção e aqueles que não a possuem, colocando-os em polos antagônicos e estabelecendo essa clivagem como o foco principal dos conflitos nas sociedades capitalistas. Desta forma, os possuidores, ou capitalistas, controlam diretamente os meios privados de produção, cabendo aos não possuidores, os trabalhadores assalariados, alienar sua força de trabalho aos capitalistas - via contrato de trabalho, pois que se tornam deles dependentes. Os primeiros enriquecem às custas do trabalho explorado, via mais-valia, e da miséria dos segundos.

A sociedade se polariza em grupos hostis de maneira a aglutinar todos os interesses que não o dos capitalistas - no polo daqueles que buscam a subversão do modelo e a mudança completa nas relações de propriedade. As contradições inicialmente circunscritas ao âmbito da fábrica logo se estendem à arena política. Por um lado, tem-se uma classe extraordinariamente grande de trabalhadores assalariados oprimidos (em suas fileiras, encontram-se aglutinados a pequena burguesia inicial, os mercadores, os pequenos industriais, os artesãos e os camponeses, todos precipitados e seduzidos pela classe proletária, portadora histórica da missão transformadora); e, no vértice da pirâmide, a pequena classe dirigente capitalista em vias de extinção.

Sob o veredicto do progresso histórico e pela lâmina da guilhotina dialética das forças sociais, há a progressão contínua dos conflitos conduzindo ao clímax revolucionário que abole, enfim, a exploração rumo à sociedade igualitária dos homens livres: a sociedade comunista.

A história da classe operária desde sua formação, no pensamento marxiano, com efeito, tornase a saga da parideira da sociedade emancipada. É nesse ponto do raciocínio de Marx que chegamos, segundo Dahrendorf, ao seu infortúnio no que se refere à análise científica das classes sociais. O historicismo e a teleologia histórica mais pura, pragas não expurgadas de Hegel, argumenta, mostrar-se-iam antes como entes que como meros fantasmas.

Atrelar necessariamente, de maneira polarizada, a posição de classe apenas ao seu componente econômico, sem levar em conta as diferenciações internas e externas constitutivas das classes sociais, como o status e os diferentes papéis sociais que cada ator 
assume em plurais esferas de sua vida e existência; e, mais que isso, cristalizar na história tais posições de origem econômica como inexoráveis, além de conceber (metafisicamente, diria ele) o proletariado como o agente incumbido de realizar a vontade histórica, significam, para Dahrendorf, a fragilidade e a utopia da empresa marxiana.

A concepção que Marx faz da sociedade comunista, observa, "de seu papel histórico e do tempo de seu surgimento, é o ponto focal da conexão entre os elementos filosóficos e sociológicos de sua teoria de classes" (DAHRENDORF, 1982, p. 37). O autor, contudo, foi conhecedor refinado da obra de Marx e não desconhece o percurso entre a formação das classes, seus antagonismos e o projeto político que aponta o conflito de classes como motor das transformações históricas.

O que ele fez é censurar o fato de a teoria de classes em Marx ser apenas parcialmente sociológica (e este mesmo talvez não negasse tal suposição se a discussão fosse colocada nesses termos) ao passo que sua validade não resistiria ao exame empírico das sociedades capitalistas contemporâneas. De fato, Marx não discutiu explicitamente a base da proposição empírica de sua teoria de classes, não deixando claro, desta feita, de maneira cabal, a natureza de suas proposições. Ao que tudo indica, entretanto, Marx deu tanta importância à teorização sobre as classes sociais que protelou sua sistematização a ponto de falecer sem tê-la levado a termo. ${ }^{12}$

\footnotetext{
${ }^{12}$ Dahrendorf, por sua vez, não hesitou em escrever tal capítulo no lugar de Marx em As classes e seus conflitos na sociedade industrial. Para ele (com uma boa pitada de ironia) e para "o leitor assíduo de Marx, não há razão para desespero. Ele pode, se o quiser, completar o capítulo no lugar de Marx - não exatamente como Marx o teria escrito, obviamente, e também não sem depender de algum tipo de interpretação, mas, de toda maneira, sem acréscimos substanciais ao que o próprio Marx disse". Dahrendorf, ao que nos parece, não se preocupou em avançar ou resolver a discussão sobre classes sociais com essa tentativa. Seu desígnio com tal empresa foi o de mostrar que Marx - e no que estamos absolutamente em desacordo -, embora tenha sido um autor sofisticado, deixou tantas pistas sobre esse assunto (classes sociais) que não haveria nada de novo caso realmente houvesse escrito o capítulo em questão. Dito de outra forma, Dahrendorf sinalizou que a teoria das classes sociais em Marx nada mais seria que especulação filosófica, filosofia da história (utópica, irrealizável) sem sustentação sociológica. Com efeito, nessa argumentação, o capítulo 52 de $O$ capital não teria ficado inacabado por falta de tempo ou necessidade de maior refinamento teórico, e sim, pura e simplesmente, por ser desnecessário.
} 


\section{CONSIDERAÇÕES FINAIS}

Dahrendorf desaprova os esquemas conceituais presentes na teoria do consenso social de Parsons, ${ }^{13}$ bem como a teoria das classes contida no pensamento de Marx, não somente por suas implicações como teoria social específica, mas antes e, sobretudo como projetos epistemológicos e filosóficos.

Numa palavra, a teoria de Parsons rejeitaria qualquer tipo de conflito constitutivo, e a teoria marxiana não reconheceria o caráter ubíquo dos conflitos ao afirmar que o conflito de classes no capitalismo se resume ao modelo dicotômico burgueses versus proletários. Ainda mais importante, o principal equívoco de Marx ter-se-ia dado ao estabelecer que esta sorte de conflito - e apenas ela - conduziria à sociedade emancipada.

A crítica epistemológica (e de visão de mundo) de Dahrendorf em relação a Parsons, portanto, reside em seu suposto caráter utópico (o que valeria também para Marx): os antagonismos e conflitos não aparecem como forças que aceleram sua própria eliminação (Marx), tampouco são momentos de não funcionalidade do sistema em equilíbrio (Parsons).

Este é um ponto no qual Marx e Parsons se encontram de maneira curiosa: ambos congelam o fluxo do processo histórico na ideia do "sistema". Se aceitamos isto, ou a mudança estrutural pode ser não existente (o que, em uma interpretação extrema, poderia denominar-se a "solução" parsoniana) ou existe apenas como mudança revolucionária (a "solução" marxista). Ambas as soluções são igualmente insatisfatórias e insustentáveis. Além disso, elas comprovam a insuficiência de todas as analogias, conscientes ou inconscientes, entre "sistemas" orgânicos e sociais. (DAHRENDORF, 1982, p. 123).

O curioso é que Dahrendorf acaba, ele mesmo, por estabelecer seu próprio funcionalismo, pois os conflitos sociais terminam contribuindo em sua visão para o ajuste

\footnotetext{
${ }^{13}$ Aqui poderiam ser alocadas algumas das várias críticas dirigidas à obra de Parsons, tais como a quase incompreensibilidade de sua terminologia técnica, a excessiva abstração em detrimento à base empírica, o conservadorismo implícito, entre tantas outras. Ver a obra referencial de Merton: Sociologia: teoria e estrutura (1970).
} 
interno da sociedade, numa espécie de "operação algébrica, na qual os contrários se anulam, gerando por sua vez outro conjunto" ${ }^{14}$

A produção de juventude de Dahrendorf, baseada na crítica ao funcionalismo e ao marxismo, levou o autor a estabelecer uma espécie de sociologia do conflito social na qual os conflitos representam o próprio sentido da história. Não estaria ele estabelecendo assim sua própria teoria da história, sua própria utopia sociológica, ainda que heterodoxamente?

\section{REFERÊNCIAS}

DAHRENDORF, Ralf. A Nova Liberdade. Brasília: Ed. Universidade de Brasília, 1979.

DAHRENDORF, Ralf. As classes e seus conflitos na sociedade industrial. Brasília: Ed. Universidade de Brasília, 1982.

DAHRENDORF, Ralf. Ensaios de Teoria da Sociedade. São Paulo: Zahar Editores e Ed. da Universidade de São Paulo, 1974.

DAHRENDORF, Ralf. O Liberalismo e a Europa (Entrevista a Vicenzo Ferrari). Brasília: Ed. da Universidade de Brasília, 1981a.

DAHRENDORF, Ralf. Sociedade e Liberdade. Brasília: Ed. Universidade de Brasília, 1981b.

DIAS JR, Antonio Carlos. O Liberalismo de Ralf Dahrendorf. Dissertação de Mestrado em Sociologia, Instituto de Filosofia e Ciências Humanas, Unicamp. Campinas, 2007.

DOMINGUES, José Maurício. A sociologia de Talcott Parsons. Niterói: Ed. da UFF, 2001.

GIDDENS, Anthony. A estrutura de classes das sociedades avançadas. Rio de Janeiro: Zahar Editores, 1975.

MERTON, Robert King. Sociologia: teoria e estrutura. São Paulo: Mestre Jou, 1970.

\footnotetext{
${ }^{14}$ Na pertinente observação de Vamireh Chacon à introdução de Sociedade e liberdade (1981b).
} 
PARSONS, Talcott. El sistema social. Madri: Alianza, 1984.

POPPER, Karl. A Sociedade Aberta e Seus Inimigos. Itatiaia/São Paulo: Ed. da Universidade de São Paulo, 1974.

POPPER, Karl. The Poverty of Historicism. London: Routledge and Kegan Paul, 1957.

\section{RESUMO}

O artigo visa reconstruir a crítica formulada pelo filósofo e sociólogo germano-inglês Ralf Dahrendorf (1929-2009) aos modelos sociológicos de Talcott Parsons e Karl Marx, que o autor considerava como utópicos. Para ele, tanto a sociologia funcionalista como a marxiana não são adequadas à análise das sociedades contemporâneas: a primeira por desconsiderar o papel constitutivo dos conflitos sociais, e a segunda por não reconhecer seu caráter ubíquo.

PALAVRAS-CHAVE: Ralf Dahrendorf ; Conflito Social; Sociologia Política

\section{ABSTRACT}

This article aims at reconstruct the critic formulated by the philosopher and sociologist german-english Ralf Dahrendorf (1929-2009) to the sociological models of Talcott Parsons e Karl Marx, that the author considers utopian. For him, such functionalist sociology as marxian does not adequate for the analysis of the contemporary societies: the first for disrespect the constitutive paper of the social conflicts, and the second for don't recognize your ubiquitous character.

KEYWORDS: Ralf Dahrendorf ; Conflito Social; Sociologia Política 